\title{
TRANSITION OF THE CONCEPTS IN OTITIS MEDIA
}

\author{
TOSHIKAZU NISHIHATA* \\ Department of Oto-Rhino-Larymgology, School of Medicine, \\ Keio University
}

(Received on February 7, 1957)

\section{INTRODUCTION}

As the pathology of otitis media has been considerably changed in recent years, the definition and the concept of otitis media should also be changed. Recently a certain group of the Japan Otological Society advocated that otitis media should be called osteitis temporalis. Actually there has been a change in the method of operative procedures for this conditions.

However, it seems to us that little attention has been paid to this question by the otologists of the world in general. Why is it?

The reasons for this question not receiving due consideration are: First, since the first article on this subject appeared in 1904 occasional papers concerning otitis media have only been partially dealt with, and the ultimate object of the research has not been clearly brought out.

Secondly, this subject not being very attractive in nature, clinicians felt no great inconvenience in not having special knowledge about it. In other words the problems of otitis media were principally changes in concept based on the date from pathology and these problems are considered to be merely an overall reform in the medical treatment or operative procedure rather than the discovery of a new method.

From the standpoint of otology, it is needless to say that the problem of otitis media is of utmost importance and the changes in concept should be regarded as a great renovation.

\section{TRANSITION OF CONCEPTS IN OTITIS MEDIA}

What I wish to present here is a systematically arranged review on this subject after surveying the old literature. Figuratively speaking, each ring of a chain had been hidden in the large number of reports regarding otitis media. That is, I had a difficult time in finding what I was looking for since they were

* Professor of Oto-Rhino-Laryngology. 
incorporated in short articles in papers with other titles.

I searched through the literature with a conviction that "mastoiditis is essentially the same as otitis media and it should not be considered as a complication of otitis media". Thus I discovered one ring after another of a chain. As I linked each ring with another it became a systematic necklace called the changes in concept of pathology of otitis media.

1. Scheibe published a report in $\mathbf{1 9 0 4}$ to an otological society in which he said "Bezold and Politzer reported that in autopsy examinations on various cases of otitis media, especially in latent cases, they found at least a portion of mastoid cells was affected together with the tympanic cavity". Therefore, in the cases of otitis media in which one elicits tenderness over the mastoid process one may be justified in considering that there exists an extensive inflammation of pneumatic cells as well as in tympanic cavity.

2. In 1912, Gustav Alexander stated that the time relation varied between the onset of mastoiditis and acute purulent otitis media. In cases of fulminant type of purulent otitis media in which suppurative changes had existed for only a few days, he found a surprising fact that mastoid process almost always did contain pus.

This is a very important report. However, because he limited this condition to "fulminant otitis media", the general impression imparted was that in cases of ordinary otitis media these findings would be different.

3. Denker-Albrecht added very important articles in his famous Text Book of Oto-Rhino-Laryngology of 1925, revised edition, as follows: In acute suppurative otitis media not only the mucous membrane of tympanic cavity is affected but also the mastoid cells are involved at the same time in a majority of cases. In spite of this being a definitive expression they explained it only under the paragraph of mastoiditis. Under the paragraph of acute otitis media they merely mentioned that inflammation was found not only in the tympanic cavity but usually over the nische of both tympanic windows and often mastoid antrum, epitympanum and distant areas of mastoid cells.

After reading these articles, one feels that while those two descriptions should completely coincide, actually they do not, and one wonders as to what was the basis of their statement. If there is no difference in the extent of inflammation between otitis media and mastoiditis, it seems clear that both should be the same disease in essence. For this reason it is important to overthrow the concept held by otologists that mastoiditis is a complication of otitis media. For this very reason Denker-Albrecht was equivocal on this point, 
and this is also true in the other literature. I could not find any date reported by them which would back up their assertion. My feeling is that their theory was based on the above mentioned views of Scheibe and Alexander. Thus they hesitated to have their writings in the same vein on the extent of inflammation between otitis media and mastoiditis.

4. In 1927, Otto Mayer reported the histo-pathological findings in mastoid cells of patients who died on the 3rd and 4th days of the illness respectively. According to this report, there was an extensive inflammation in mastoid areas.

5. In 1928, Lange reported on the findings of the mastoid cells in the cases of patients who died on the 4th to 10th day after the onset of otitis media, added the following: Mastoiditis should not be lightly considered a result of tympanitis. Rather it should be considered an accompanying phenomenon. Although clinically no proof can be made, it can often be found that each one has its own independent nature. But in all cases of otitis media inflammation seems to coexist in mastoid aircells. Histological examination always reveals an inflammation in the mastoid aircells.

6. In 1928 Krainz found on the 2nd day of an otitis media a bony necrosis in vascular channels in near and distant areas of the mastoid.

7. In the same year Schlittler reported a case in which mastoititis occurred in the first day of otitis media. However, this case was complicated with meningitis, sinus thrombosis, labrinthitis or brain abcess.

8. In 1928, in connection with his case report, 0 . Mayer stated that acute mastoititis is not a result of acute otitis media but it is a part of the same phenomenon. That is, the acute mastoititis is not a complication but is an inflammation of otitis media which has localized in mastoid.

9. In 1929, Portmann published a paper on mastoid reaction in which he stated that in acute otitis media mastoid cells are sometimes involved at an early stage.

10. Since 1925, I have wondered as to what the real nature of mastoiditis is,

(a) Tenderness, swelling of the mastoid portion, and sagging of the postsuperior external canal wall are clinical signs which clinch the diagnosis of mastoiditis. However, in certain cases of otitis media in which these typical symptoms are lacking profuse discharge from the ear is noted.

As the source of such profuse discharge I could not ascribe to a lesion of a small and simple tympanic cavity only.

It seems rational to consider that the source of the discharge lies in 
deeper portions of the temporal bone, for example mastoid cells and pyramid cells.

(b) If otitis media is simply a tympanitis, we can cure it easily by paracentesis. But this is not always the case.

(c) By observation of some acute cases, which show no distinct symptom of mastoiditis and yet tend to become chronic, I cannot help thinking that the lesion lies in deeper and wider areas than tympanic cavity.

On the basis of these findings I began to think that even in the cases of ordinary acute otitis media the mastoid cells would be affected in the early stage.

For several years this question hovered over my mind, but I could not carry out an experiment on animals because only a monkey has mastoid cells similar to man, and to secure this animal was economically prohibitive to me. However, my views mentioned above were rapidly strengthened by clinical observation.

11. In 1931, Link reported on decided changes of conception on mastoiditis and otitis media. While the substances of his paper did not concur with my views, there were some common points. The summary of his paper is as follows:

(a) Although it is called mastoiditis the area of operation often is in petrous portion or zygomatic bone and is not squamous portion. Cells around the Eustachian tube and "perilabyrinthäre Zelle" are not in mastoid process.

(b) The word mastoiditis suggests osteomylitis, but it is the mastoid pneumatic cells which are principally involved and an involvement of bonemarrow is rare. It is better to call it cellulitis.

(c) The matter most related to my study is Link's conception of otitis media being extended widely to include mastoiditis and petrositis.

What I wish to call the attention of the readers here is the fact that he makes no mention of when the mastoid or pyramid is affected in otitis media.

This is very important, and the lack of mentioning the time of the mastoid and pyramid involvement negates the greater portion of his argument. If the mastoid or pyramid is affected secondarily at later period of the otitis media, it is not illogical to consider that the mastoiditis or petrositis is a complication of otitis media.

The circumstances will become different if the inflammation would begin at the mastoid or pyramid with or at an early stage of infection in the tympanic cavity. Link's theory would have been most valuable and he confirmed this fact. It is strange that in his reports Link did not touch on this point at all. I do not know whether he had reported on this study before. At least some reference 
should have been made in his paper on data which I have mentioned above. This point I cannot understand but there is no way of confirming this fact because of his death.

12. In 1935, I had the opportunity of operating on 3 cases of otitis media on the 2nd-5th day after the onset. In spite of these cases not exhibiting any symptoms of mastoiditis, a purulent inflammation in the mastoid cells was noted. These cases were reported at the Otology society. Subsequently I encountered numerous similar cases. I found that sometimes inflammation in the mastoid cells occurred at late as 20 days after the onset of otitis media and in very few cases were the mastoid cells unaffected.

The most important point I wish to bring out, however, is that there are many cases in which the mastoid cells are affected at an early stage of, or with the onset of acute otitis media. The percentage of those thus affected could not be determined because of the infrequency in encountering such cases. With Miyakogawa I carried out histopathological examination on operated cases and found pathologic changes not only in the mucous membrane but in the bone as well. This I reported in the Monatschrift of Germany in 1941.

13. In 1938, Hermann Marx described, in the new edition of his "Kurzes Handbuch", the relationship between otitis media and mastoiditis, but it is difficult to grasp his meaning because of his lack of consistency. For instance he states "in the case of exudative inflammation of the tympanic cavity, mastoid cells are always involved but this is found only in a hematogenic infection, and in cases of tubal infection, the tympanic cavity is first affected and subsequently the infection extends to mastoid cells".

This view is nothing new, but in subsequent pages he describes that "in almost all cases infection extends to the mastoid cells through the mucous membrane. If this is called mastoiditis, any kind of otitis media is related to mastoiditis". He cites the cases of Schlittler.

Perhaps he considers histopathological definition of mastoiditis too serious and he must be considering that fact that it should not be called mastoiditis if inflammation extends to mucous membrane only.

There are many views on the definition of mastoiditis but the focussing point is directed by the histopathological findings; and from a clinical standpoint one cannot establish it definitely. But usually the diagnosis of mastoiditis is made clinically and it is not a clear-cut definition.

A more important matter is to know when the inflammation does attack the mastoid cells. It is clear in the literature that inflammation is recognized 
only in the mucous membrane macroscopically but by histological investigation one finds bony changes are accompanied. So, there is no essential difference whether one calls it mastoiditis, mastoid reaction or mastoidismus.

The fact that inflammation affects mastoid cells or the pyramid at an early stage of otitis media explains the pathology of otitis media and the mechanism which causes endocranial complication before clinical diagnosis of mastoiditis or petrositis is made.

Now I would like to change my subject to the petrous pyramid.

14. In 1930, Belinoff and Balan investigated the pneumatic cells of the petrous apex and observed that such cells were developed in $28 \%$ of all cases in which mastoid cells had not been found, and they warned the danger of the inflammation spreading into the petrous apex before affecting the mastoid cells.

15. In 1936, Pietrantoni of Italy, published the results of X-ray examination in which he stated that in cases of otitis media, inflammation may spread to petrous apex as well as mastoid process.

16. At about the same time J. Oda of Japan investigated histologically the pyramid in an otitis media patient who died of other complications, and found healed lesions of the pyramid which had been affected unnoticed. There were not a few cases in which inflammation had extended unnoticed to the pyramid in otitis media and it was easily conceivable that cerebral complication might thus ensue.

Link's paper would have established this point had he focused on this fact, but he failed to mention this. It might have been a discussion by presumption. Any way his intention was right.

17. In 1942, Sawatari and Niho called otitis media as "ostitis temporalis" and advanced a new classification. I shall not describe it here but it resembles Link's.

It is not enough that they base their theory simply on "Portmann's Mastoidreaction", "Alexander's Mastoidismus" and "Kosokabe's Ausgedehnte Otitis Media Akuta". As these are special forms in special cases, it is not the consideration which concerns otitis media as a whole. However, Sawatari and Niho did not cite above mentioned studies concretely and mentioned only "recently some otologists recognized that all pneumatic cells of the temporal bone in so-called ordinary otitis media are affected almost at the same time and...."

It is regretable that they give the impression in their writing that by Link's theory we have discovered it for the first time. The contrary is self eviding if one refers back to the literature chronologically. Anyway, we must recognize 
the fact that Niho courageously declared in the Otological Society that otitis media is ostitis temporalis. It is evident that, if we continued our study, we would obtain the same result without fail.

Let us see the views which members of the Japan Otological Society hold on this question.

18. Torii is opposed to the idea of including mastoiditis into the category of otitis media.

This may be confirmed in the chapter on otitis media in "Oto-Rhino-Laryngology" which was edited jointly with Konno. In essence Torii's views are as follows :

He still holds the view formerly held that mastoiditis is a complication of otitis media. The reasons are 1) There is little or no foundation that mastoiditis is to be considered as a partial phenomenon of otitis media. 2) As is noted in the same respiratory canal, there being rhinitis, pharyngitis and bronchitis, there should be no objection to consider that in the ear there are otitis media and mastoiditis.

The second point is a false analogy and a figure of speech. He considers one thing which has different characteristic to another that does not. The temporal bone is in itself an anatomical unit.

An interesting thing is that Torii contradicts himself in his argument. For instance, he said that it should be properly considered that otitis media does no heal because of the mastoid inflammation which developed at the same time with the otitis media, keep on, rather than to consider mastoiditis developing as a result of unhealed acute otitis media.

Isn't this statement simply expressing our theory in reverse?

In spite of his argument that acute mastoiditis and petrositis are the complications of otitis media and making no comment whatever upon the mastoid and pyramid a paragraph on acute otitis media, he estimated in the paragraph on endocranial complication that the frequency of endocranial complications of infection in the mastoid, pyramid and labyrinth would be one third each. Thus each of these three conditions has almost the same percentage. That means, when endocranial complication of otitis media is discussed the whole of the temporal bone is discussed as one object. He may argue that endocranial complication may be the result of complication occurring in mastoid or pyramid. But it is well known fact that endocranial complication may occur before the appearance of symptoms of mastoiditis or petrositis.

19. Apart from this factors, recently (1944-1951) Niho, Yoshio and Ishikawa 
clinically proved that bone necrosis had been found in the pyramid in ordinary acute otitis media. This finding may be said to reenforce their theory.

20. Mitsuharu Goto stated in Japans 1952 edition of Oto-Rhino-Laryngology that since mastoiditis may occur primarily, it is better to keep it as a separate entity. But I cannot concur with his view because he merely cites a rare occurrence such as syphilis.

Incidentally, I consider the subject of chronic otitis media extremely interesting.

In 1940, M. Miyao observed a case of chronic catarrhal otitis media and confirmed the same fact as that which I have been propounding in acute otitis media. He attached little importance to my reports of 1935 and the above mentioned studies, he only cites Richter's case and quotes that Torii has held the same views as ours.

In 1948, Isono reported that in the surgical operation of the epitympanic form of chronic purulent otitis media there was noted pathologic changes not only in the attic but also in the entire mastoid in sixty percent of 500 cases.

At about the same time Niho operated on the pyramid of a chronic otitis media patient and found changes in the bone.

Judging from these, it may be considered that in chronic otitis media, mastoids and pyramids are also affected, in many instances. It is of interest to note that these changes are found not only in purulent forms but in catarrhal conditions as well.

Scanning the extent of the inflammation of chronic and acute otitis media, it may be said that the inflammation does extend to all parts of the temporal bone and the lesions develops in many cases over these areas at the same time as the onset of otitis media.

Now we can no longer consider that there is paucity or lack of data on this subject.

At this point I would like to draw conclusion that when considering pathology of otitis media one should include the entire temporal bone as an objective. Therefore Niho's contention that otitis media means osteitis temporalis is not a mistake. However, I cannot agree with his proposal that the nomenclature of otitis media should be abandoned and we should replace it with the name of osteitis temporalis.

My reasons of disagreement on this proposal are (1) the name of otitis media is so well known not only to the otologist but also to the general public. Changing the name to osteitis temporalis will cause too great a confusion. 
(2) While the name of otitis media indicates directly the disease of auditory organ, the name of osteitis temporalis gives no such impression. It removes the impression of its being related to the ear.

On these two points I cannot agree with Niho. I would like to have the name of otitis media kept as heretofore and the term osteitis temporalis be employed as a pathological terminology.

Here I would like to add one thing and that is that even if there is osteitis temporalis, not all areas of temporal bone are attacked in all cases of otitis media.

There is a difference of pneumatisation in different individuals. There are cases in which inflammation is limited or extended to typanum, antrum, mastoid or pyramid and sometimes only the pyramid is involved leaving the mastoid free. No doubt there may be many stages in its course, so the forms also may be varied. But in almost all cases not only tympanum, but mastoid and pyramid. are affected though the severity may be different.

At least we should always keep our mind open to all areas of temporal bone in dealing with otitis media. There is no longer any question as to otitis media being osteitis temporalis. Therefore, although it may not be a mistake to consider mastoiditis and petrositis as distinct complication of otitis media, it may be said that it is not logical.

Leaving the discussion aside, so long as the existence of inflammation in the temporal bone is proven, the operative method should be revised accordingly.

In 1943, Kozo Takahara pointed out that in the so-called radical middle ear operation which gives little or no consideration of curetting the pyramid, the term of radical operation is not well chosen because there is about one in ten cases in which discharges from the ear do not cease. He suggests calling the radical operation that which involves a surgical procedure beyond certain demarcation. This demarcation is a line proposed by $O$. Mayer and is one which is tangent to the apex of anterior border of the apex of bony cochlea.

In 1944, M. Niho advocated so-called radical os temporal operation. This. method is a combination of various pyramid operations in accordance with the state of the lesion or pneumatization. Taking the most extensive lesion for instance involves an exposure of dura superiorly by Streit's method, exposure of sinus sigmoideus posteriorly by Yamashita's method, anteriosuperiorly by Voss method, and anteriorinferiorly by Ramadier's method.

The extent of curettage from the perilabyrinth to the petrous apex is governed by each different case. Not only macroscopically affected cells but carious bones 
and marrows are to be curetted till compact bony tissues are exposed.

I investigated as to wherein lies the area of insufficient curettage in about 10 cases of chronic otitis media in which operation had been done previously by other otologists or by myself. Those cases in which cure was not effected after surgical intervention were largely due to diseased areas which were left out in the perilabyrinth. The most difficult cases were those in which lesions were found in anterior-superior cells of pyramid, hypotympanum cells, Eustachian tube cells and anterior-inferior cells of pyramid.

On investigation of removed bony specimens various changes were noted. The severely affected part of the bone, of course, showed a bony destruction but this was neither as extensive nor as highly severe as seen in acute otitis media. Therefore, in spite of healing which might be expected with the chemotherapeutic use of Penicillin, Aureomycin and Sulfamin drugs, in few cases a cure was not obtained at the end of a month's treatment. In the majority of above mentioned cases, pathologic changes were recognized in pyramid and cells around Eustachian tube.

The most commonly observed bone changes are bony absorption (halisteresis) and disappearance of nucleus of bony cells and these changes are usually to be seen even in grossly healthy bones. These findings are considered significant also from a clinical standpoint because these changes are considered as bony necrosis (without sequestration) and nothing could be done even with the use of antibiotics. The resistance of the reinfection may be such that there is no way of bringing cure unless removed by surgical operation.

I have seen a few cases in which the bony changes which resisted healing by operation and which did not form epithelium covering were simply due to microscopic bony absorption and bone cells disappearance. Therefore, it is to be considered that such bony changes might become a causative factor in retarding cure of the operated lesion. But it cannot always be said that the presence of the bony changes does not necessarily mean that healing would not take place with epithelial formation. But radical middle ear operation or modified radical operation chronic purulent otitis media has been brought to cure in many cases. Strictly speaking, bony changes are to be considered as present in the bony portions of Eustachian tube and hypotympanum in such cases.

I quite agree with the opinion that from the standpoint of pathology, acute or chronic otitis media is osteitis temporalis and I maintain that mastoiditis or petrositis are essentially not the complication but a part of the extensive pathologic changes of otitis media. 
Therefore, I believe it is necessary to revise the described in the current text books of otitis media which seems to have been considered as tympanitis. As a result, in dealing with otitis media, one should carry out the operation in relation to the pathology involved, namely the entire temporal bone as an objective. In actual practice, however the extent of curettage differs in each case. Radical mastoidectomies or modified radical mastoidectomies may suffice in some cases while others may require curettage to and including petrous apex.

That the curative operation of osteitis temporalis requires a considerable time is easily understood. In spite of such an operation one may encounter cases in which the discharge continues from the auditory canal.

The recently published Lempert's Modern Temporal Bone Surgery gives no mention of the pathology and curettage with respect to the diseases of petrous portion. On this point I am not thoroughly satisfied but of the tympanum, carotid wall, tensor muscles, hypotympanum and other his detailed methods of curettage are admirable. If the result of curative temporal bone operation is not satisfactory, it is due very often to a careless curettage of those portions which Lempert strongly emphasizes in his report.

\section{CONCLUSION}

1. In almost all cases of acute purulent otitis media, the inflammation does extend not only to the tympanic cavity but also into the mastoid process and pyramid.

2. Mastoiditis and Petrositis are to be considered a part of the extensive pathologic changes rather than a complication of acute otitis media.

3. I agree with the theory that the acute otitis media is osteitis temporalis.

4. This priciple can be applied in chronic purulent otitis media.

5. Basically the surgical operation of otitis media should have all the parts of the temporal bone as an objective. However, the radical mastoidectomy and modified radical mastoidectomy as currently employed have their place depending on the cases.

6. Chemotherapy cannot completely cure the bony changes of chronic otitis media. It is considered these agents will not reach the deep areas and they lack the power of rendering regeneration of the bony necrosis.

\section{REFERENCES}

1. Scheibe, A.: Meine Lehre vom Empyem: Warnung vor der Bezeichrung "Mastoiditis". Ztschr. Hals- Nasen- u. Ohrenh., 14: 583, 1926. 
2. Alexander, G.: Mastoidsymptome im Beginn der Otitis Media, in Vogel: Die Ohrenheilkunde im Kindesalter, p. 174, 1912.

3. Denker, A., \& Albrecht, W.: Lehrbuch der Krankheiten des Ohres und Luftwege einschliesslich der Mundkrankheiten. Jena, Gustav Fischer, 1925.

4. Mayer, O.: Zur Pathologischen Anatomie der Mastoiditis und Zur Kenntnis der Überleitungswege zu den Meningen bei akuter Mittelohrentzündung. Ztschr. Hals- Nasen- u. Ohrenh., 20: 149, 1928.

5. Lange, W.: Die Pathologische Anatomie der Mastoiditis. Ztschr. Hals- Nasenu. Ohrenh., 20: 3, 1928.

6. Krainz, W.: Zur Pathologie der Mastoiditis. Ztschr. Hals- Nasen- u. Ohrenh., 20 : 144, 1928.

7. Schlittler, E.: Ein Klinischer Beitrag zur Indikationsstellung bei der Operation der akuten Mastoiditis und zur Rolle des Empyems als Teilerscheinung derselben. Ztschr. Hals- Nasen- u. Ohrenh., 19: 362, 1927.

8. Portmann, G.: La mastoidite. 1929.

9. Link; A.: Inwieweit entsprechen die Begriffe "Otitis media" und "Mastoiditis" unseren heutigen Anschauungen und Anforderungen einer klaren, zweckmässigen Krankheitsbereichnung? Arch. Ohren- Nasen- u. Kehlkopfh., 129: 181, 1931.

10. Nishihata, T.: Beiträge zur Pathologie der Mastoiditis. Monatsschr. Ohrenh., 75: 31, 1941.

11. Marx, H.: Kurzes Handbuch der Ohrenheilkunde. Jena, Gustav Fischer, 1938.

12. Oda, J.: Über die Bedeutung der Pyramidenspitzeneiterung für die Entstehung der otogenen Meningitis. Ztschr. Otol. Rhin. Laryng. Japan, 44: 701, 1938. (in Japanese)

13. Lempert, J.: Modern Temporal Bone Surgery: History of its Evolution. Laryngoscope, 60: 740, 1950.

14. Sawatari, J., \& Niho, S.: Über eine neue Einteilung der Ostitis temporalis (Sog. Otitis media im weiteren Sinne). Ztschr. Otol. Rhin. Laryng. Japan, 48: 910, 1942. (in Japanese)

15. Niho, S., Yoshio, K., Iwatake, T., \& Takahata, N.: Petrositis and Osteomyelitis Temporalis. Yokohama M. Bull., 5: 125, 1954. (in Japanese)

16. Isono, S.: The Pathology of Otitis Media. Otolaryng. Tokyo, 20: 11, 1948. (in Japanese)

17. Miyao, M.: On an Interesting Case of So-called Chronic Catarrhal Middle-Ear Inflammation. Jibi-inkoka Rinsho Japan, 35: 852, 1940. (in Japanese)

18. Niho, S., \& Ishikawa, M.: Cure of Chronic Petrositis only after Radical Temporal Bone Operation: Case report. Otolarying. Tokyo, 23. 50, 1951. (in Japanese)

19. Niho, S.: Beiträge zu Fällen von Petrositis, besonders über die Indikation der direkten operativen Eingriffe bei Petrositis, und Verteidigung des neuen Namen "Radikaloperation der Ostitis Temporalis". Ztschr. Otol. Rhin. Laryng. Japan, 50: 41, 1946. (in Japanese) 


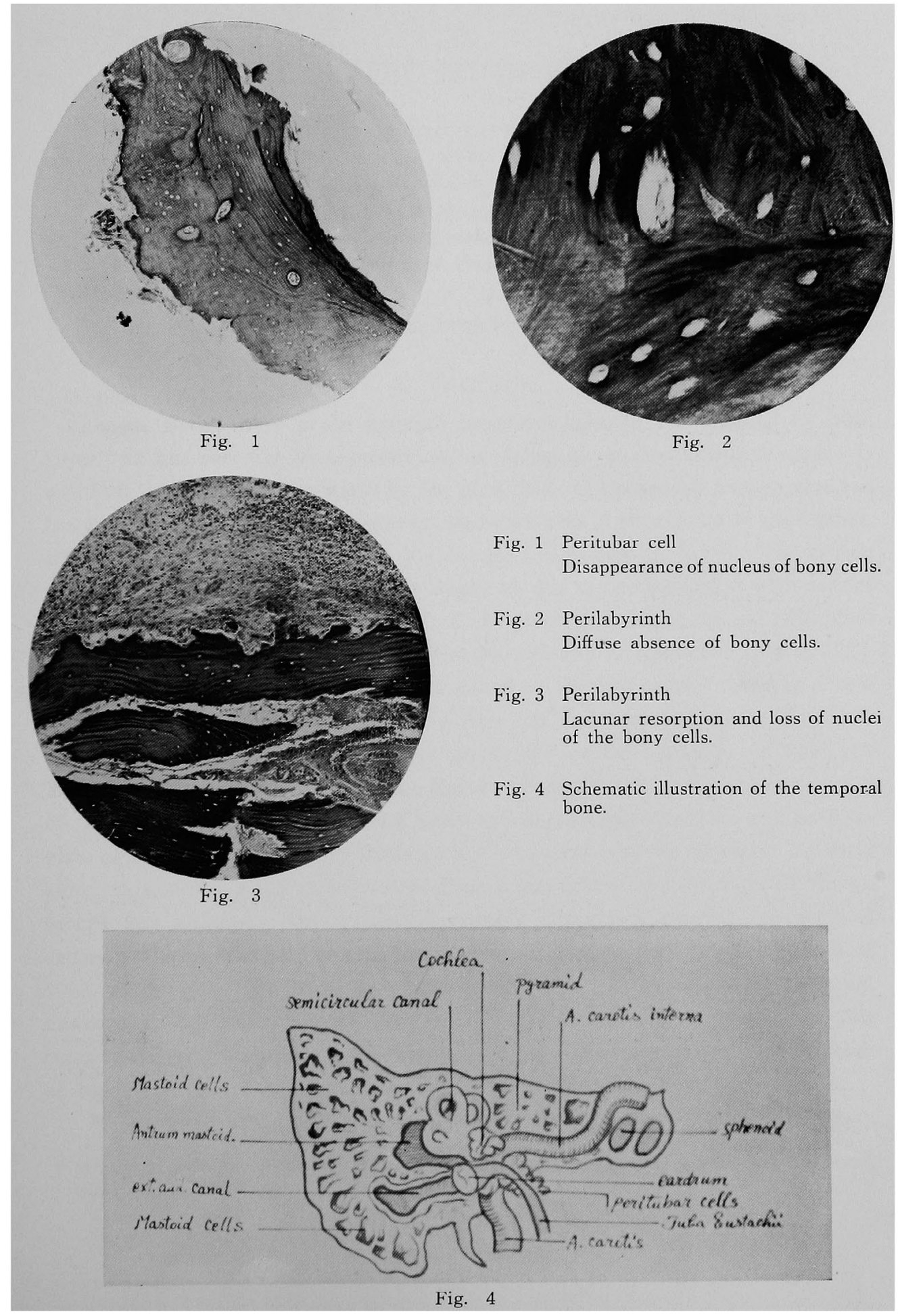

